\title{
The Effect of Energy Levels of the Electron Acceptor Materials on Organic Photovoltaic Cells
}

\author{
Hassen Derouiche*, Sami Saidi, Abdelatif Belhadj Mohamed \\ Laboratoire de Photovoltaïques, Centre de Recherches et des Technologies de l'Energie, Hammam-Lif, Tunisia. \\ Email: hderouiche@yahoo.fr, hassenderouiche@isste.rnu.tn \\ Received March 10, 2011; revised May 21, 2011; accepted May 28, 2011.
}

\begin{abstract}
Organic photovoltaic cells have been fabricated using copper phthalocyanine CuPc as electron donor and C60 or PCBM as electron acceptor. We have investigated the I-V measurements of two different structures: ITO/PEDOT: $P S S /(C u P c$ : $C 60$ or $C u P c: P C B M) / B C P / A l$. We have observed that the substitution of PCBM by $C 60$ scales up the photocurrent and the efficiency of the devices. As for the open-circuit voltage and the fill factor, we have seen that Voc and FF depend on the energy difference between the highest occupied molecular orbital (HOMO) of CuPc and the lowest unoccupied molecular orbital (LUMO) of C60 or PCBM.
\end{abstract}

Keywords: CuPc, C60, PCBM, Energy Levels, Organic Photovoltaic Cells

\section{Introduction}

Organic photovoltaic cells have recently attracted considerable attention because they are low cost and easy to process [1-4]. Photoactive layer can be created by blending these small molecules together; this molecule/molecule junction is named bulk heterojunction. The most suitable condition to establish efficient exciton dissociation in a bulk heterojunction is that the $\mathrm{LUMO}_{\text {molecule }}{ }^{>}$ $\mathrm{LUMO}_{\text {molecule2 } 2}$ and $\mathrm{HOMO}_{\text {molecule } 1}>\mathrm{HOMO}_{\text {molecule2 }}$ and the difference between these levels respectively is higher than the binding energy of a photo-generated exciton. The molecule2 can accept an electron from the conduction band of the molecule 1 and is therefore called electron acceptor (A). So, the molecule1 is the electron donor (D).

In this work, the copper phthalocyanine was chosen as photoactive dyes. $\mathrm{CuPc}$ is used as electron donor, which has a significant absorption in the visible spectral range $[5,6]$. Fullerene C60 and the fullerene derivative PCBM ([6,6]-phenyl-C61-butyric acid methyl ester) are used as electron acceptor $[7,8]$. Therefore, blending these materials is thought to be very promising as photoactive layer for photon-to-electric energy conversion. In addition, a hole blocking layer, bathocuproine (BCP), is inserted between the organic photoactive layer and the aluminium cathode and an electron blocking layer, Poly (3,4-ethylene dioxythiophene): poly (styrenesulfonate), PEDOT:PSS, on top of the indium tin oxide ITO anode (Figure 1).
The aim of this work is to present the effect of energy levels of the electron acceptor materials on organic photovoltaic cells and to investigate the implication of the electrostatic forces resulting from the energy difference between $\mathrm{HOMO}_{\text {Donor }}-\mathrm{HOMO}_{\text {Acceptor }}$ and $\mathrm{LUMO}_{\text {Donor }}$ $\mathrm{LUMO}_{\text {Acceptor }}$ levels of organic materials on the photocurrent and on the efficiency of copper phthalocyanine based organic solar cells.

\section{Experimental Details}

Photovoltaic devices have been fabricated using spin coating and thermal co-evaporation processes. The organic active layers have been deposited between ITO/PEDOT: PSS as photo-anode and $\mathrm{BCP} /$ aluminium as photocathode.

The PEDOT: PSS (BAYER) has been spin-coated onto the ITO coated glass. The copper phthalocyanine $\mathrm{CuPc}$ (99\% purity), fullerene C60 (99.99\% purity) and fullerene derivative [6,6]-phenyl-C61-butyric acid methyl ester (PCBM, 99.5\% purity) were purchased from Aldrich and used without further purification. In this work, in a nitrogen atmosphere at ambient temperature in a glove box, CuPc: PCBM or CuPc: $\mathrm{C} 60$ were dissolved into a mixed dichlorobenzene and trifluoroacetic acid solution at a weight ratio $3: 1$ and deposited using doctor blade technique. The thickness was checked by cross section visualization using a scanning electron microscope (SEM). 


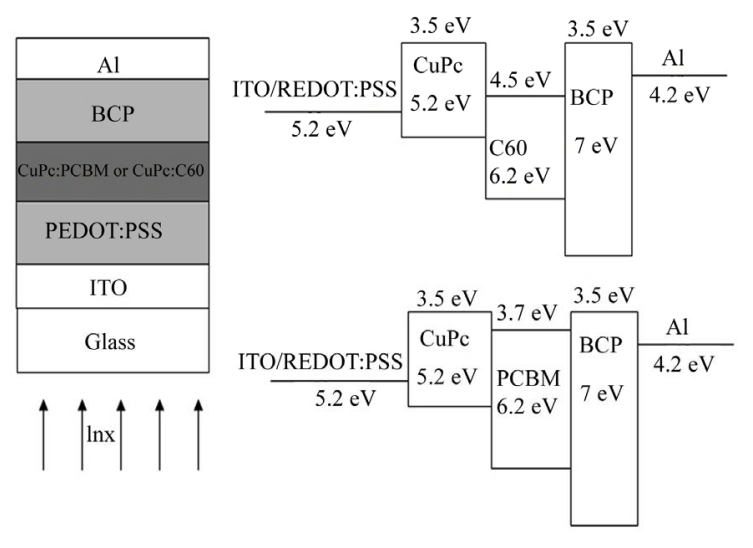

Figure 1. Structure and energy diagram of the solar cells: ITO/PEDOT: PSS/CuPc: PCBM or CuPc: C60/BCP/AI.

Finally, Bathocuproine (BCP, $99.99 \%$ purity) and aluminium contacts were deposited using vacuum evaporation at a pressure of $10^{-5} \mathrm{~Pa}$. After thermal evaporation, the devices were to be annealed at $140^{\circ} \mathrm{C}$ for $5 \mathrm{~min}$.

To study the properties of the different samples, photoactive layers were subject to ultraviolet-visible absorption spectrophotometry and atomic force microscope (AFM). The photovoltaic properties of the cells were studied by current voltage (I-V) measurements under a solar simulator generating AM1.5 light $\left(1000 \mathrm{~W} / \mathrm{m}^{2}\right)$ irradiance.

\section{Results and Discussion}

AFM (Figure 2) observations allow to follow the evolution of the surface morphology and the structure of the CuPc: C60 and CuPc: PCBM thin films. They clearly show the presence of dense packing film with a smooth surface. The blended CuPc: C60 films Figure 2(d) appear as a CuPc planar molecules blended with C60 nearspherical shape molecules (Figure 2(b)); the bulk heterojunction is randomly distributed in a homogeneous matrix. This proximity of the electron donor molecules and those of $\mathrm{CuPc}$ acceptor is essential for charges transport. The films made from CuPc: PCBM blend (Figure 2(e)) have a smoother morphology than that of the pure CuPc and PCBM films. CuPc: PCBM surface morphology shows PCBM islands surrounded by $\mathrm{CuPc}$ molecules. The AFM measurements confirm the formation of a good bulk heterojunction - both at the level of CuPc: PCBM and CuPc: $\mathrm{C} 60$ - which should improve exciton separation and charges transport and consequently enhances photocurrent and power conversion efficiency of the solar cells.

Figure 3 shows the absorption spectra of $\mathrm{CuPc}, \mathrm{CuPc}$ : $\mathrm{C} 60$ and $\mathrm{CuPc}: \mathrm{PCBM}$. CuPc has a strong electro- nic transition varying from 300 to $800 \mathrm{~nm}$, with the typical three absorption peaks related to the $\pi-\pi^{*}$ transition at around 340, 630 and $740 \mathrm{~nm}$. For CuPc: PCBM film, the

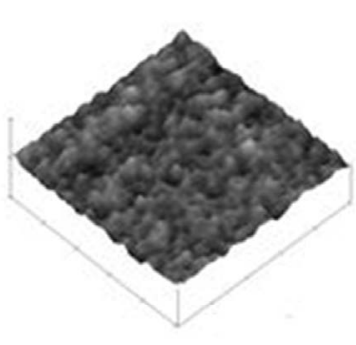

(a)

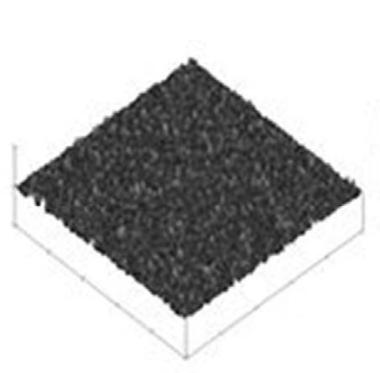

(c)

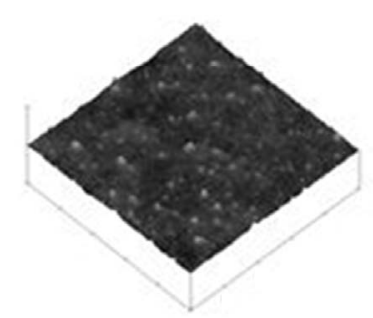

(e)

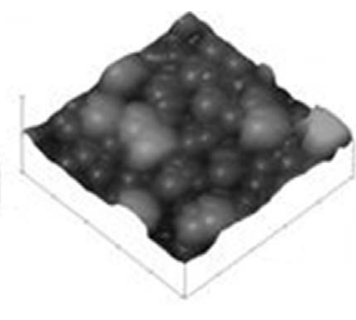

(b)

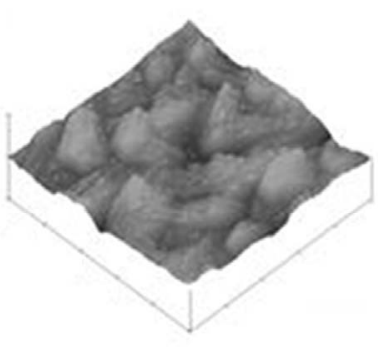

(d)
Figure 2. AFM images of a) PCBM, b) $\mathrm{C60}$, c) $\mathrm{CuPc}$, d) CuPc: PCBM and e) CuPc: C60.

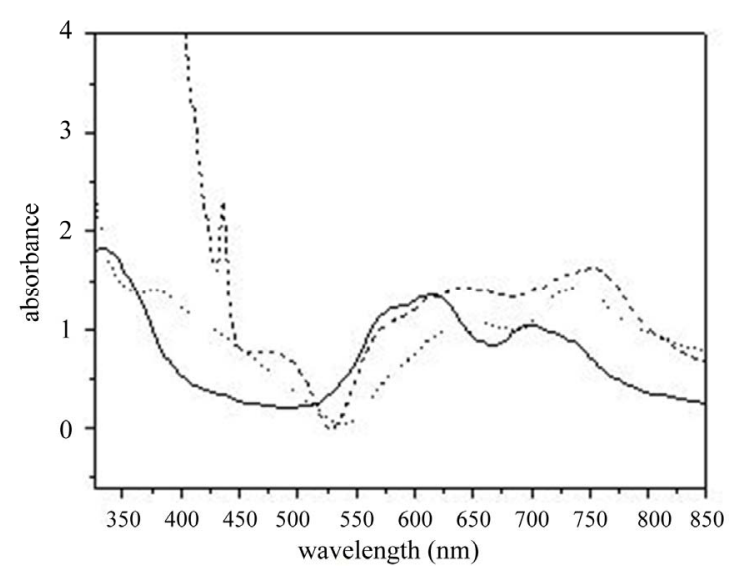

Figure 3. The absorbance spectra of: CuPc (solid line), CuPc: PCBM (dashed line) and CuPc: C60 (dotted line).

peak at around $430 \mathrm{~nm}$ comes from the absorption of PCBM. For CuPc: C60 film, the broad absorption band in the range of $300-550 \mathrm{~nm}$ comes from the absorption of C60 [9].

The I-V characteristics of the ITO/PEDOT: PSS/(CuPc: 
$\mathrm{C} 60$ or $\mathrm{CuPc}: \mathrm{PCBM}) / \mathrm{BCP} / \mathrm{Al}$, under illumination are plotted in Figure 4. ITO/PEDOT: PSS $(50 \mathrm{~nm}) / \mathrm{CuPc}$ : C60 $(50 \mathrm{~nm}) / \mathrm{BCP}(5 \mathrm{~nm}) / \mathrm{Al}$ device develops an open circuit voltage $\mathrm{V}_{\mathrm{OC}}$ of $0.4 \mathrm{~V}$, a short circuit current Isc of $4.03 \mathrm{~mA} / \mathrm{cm}^{2}$, a fill factor of 0.26 and an energy conversion efficiency of $0.43 \%$. As for ITO/PEDOT: PSS (50 $\mathrm{nm}) / \mathrm{CuPc}: \mathrm{PCBM}(50 \mathrm{~nm}) / \mathrm{BCP}(5 \mathrm{~nm}) / \mathrm{Al}$, we have a $\mathrm{V}_{\mathrm{OC}}$ of $0.52 \mathrm{~V}$, an ISC of $1.53 \mathrm{~mA} / \mathrm{cm}^{2}$ and a fill factor of 0.34 giving energy conversion efficiency of $0.27 \%$. We can see that the combination of CuPc: $\mathrm{C} 60$ or CuPc: PCBM present an energy diagram which leads to excitons splitting and charges transfer. We know that organic semiconductor materials excitons are strongly selfbounded and dissociated at the $\mathrm{D} / \mathrm{A}$ interface. The energy discontinuity between LUMO CuPc and LUMO C60 is larger than that between $\mathrm{CuPc}$ and PCBM. The same can be said about HOMO level. So, the resulting field (the potential gradient at the junction) can overcome the exciton self-binding energy, which makes charges separation better at the interface $\mathrm{CuPc}$ : $\mathrm{C} 60$ than $\mathrm{CuPc}$ PCBM. Moreover, experimental results have shown that a better short circuit current and efficiency is obtained with CuPc: C60 (Table 1). A better ISC and $\eta$ may be obtained when LUMOs and HOMOs of the blended components have a strong offset of the band edges in order to split the excitons [10].

On the other hand, with CuPc: C60, both the opencircuit voltage and the fill factor decrease, respectively, to a value around $0.4 \mathrm{~V}$ and 0.26 compared to $0.52 \mathrm{~V}$ and 0.34 found in devices with CuPc: PCBM (Table 2). Therefore, we can note that the open-circuit voltage and the fill factor depend on the difference between the HOMO of the donor and the LUMO of the acceptor: (HO$\mathrm{MO}_{(\mathrm{CuPC})}-\mathrm{LUMO}_{(\mathrm{C} 60 \text { or PCBM) }}$ [11].

The efficiency $\eta$ is defined as: $\eta=\mathrm{I}_{\mathrm{SC}} \cdot \mathrm{Voc} \cdot \mathrm{FF} / \mathrm{P}_{\mathrm{inc}}$, where $\mathrm{P}_{\text {inc }}$ is the incident power density. When compar-

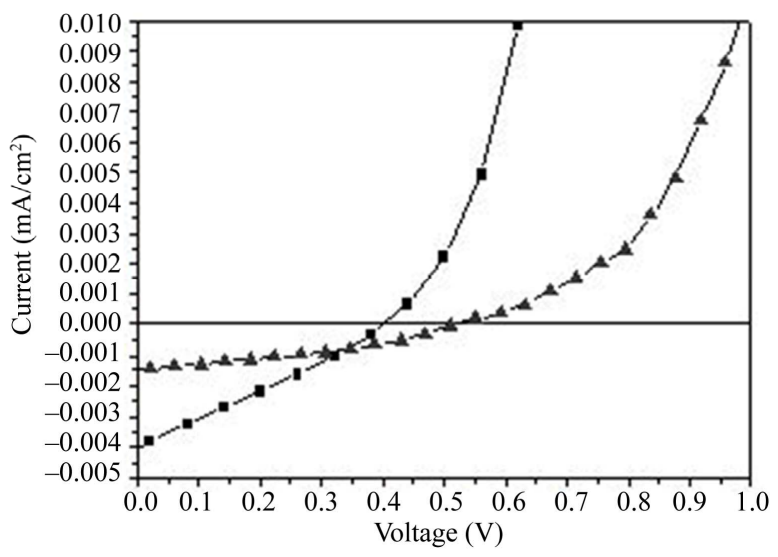

Figure 4. I (V) characteristics of: ITO/PEDOT: PSS/CuPc: C60/BCP/Al (ø); ITO/PEDOT: PSS/CuPc: PCBM/BCP/Al (४).
Table 1. The energy differences in LUMO and HOMO, and the efficiency.

\begin{tabular}{ccc}
\hline & CuPc: C60 & CuPc: PCBM \\
\hline $\begin{array}{c}\text { HOMO(Donor)-HOMO } \\
\text { (acceptor) }\end{array}$ & $1 \mathrm{eV}$ & $0.2 \mathrm{eV}$ \\
$\begin{array}{c}\text { LUMO(Donor)-LUMO } \\
\text { (acceptor) }\end{array}$ & $1 \mathrm{eV}$ & $1 \mathrm{eV}$ \\
Isc & $4.03 \mathrm{~mA} / \mathrm{cm}^{2}$ & $1.53 \mathrm{~mA} / \mathrm{cm}^{2}$ \\
$\eta$ & $0.43 \%$ & $0.27 \%$ \\
\hline
\end{tabular}

Table 2. The HOMO (CuPc)-LUMO (C60 or PCBM), opencircuit voltage and fill factor.

\begin{tabular}{ccc}
\hline & CuPc: C60 & CuPc: PCBM \\
\hline HOMO $_{\text {(Donor) }}-$ LUMO $_{\text {(acceptor) }}$ & $0.7 \mathrm{eV}$ & $1.5 \mathrm{eV}$ \\
Voc & $0.4 \mathrm{~V}$ & $0.52 \mathrm{~V}$ \\
$\mathrm{FF}$ & 0.26 & 0.34 \\
\hline
\end{tabular}

ing ITO/PEDOT: PSS/CuPc:C60/BCP/Al and ITO/PEDOT: PSS/CuPc: PCBM/BCP/Al devices, we can observe that the increase of efficiency is due to the increase of the photocurrent ISC which compensate the decreasing of both Voc and FF.

\section{Conclusions}

An organic small molecule photovoltaic devices, ITO/ PEDOT: PSS/CuPc: $\mathrm{C} 60 / \mathrm{BCP} / \mathrm{Al}$, have been fabricated and show improvement in performance compared to ITO/PEDOT: PSS/CuPc: PCBM/BCP/Al devices. A better photocurrent and a better efficiency have been obtained when LUMO and HOMO of the blended components have a strong offset of the band edges. Moreover, in the case of CuPc: C60 active layer, the open-circuit voltage and the fill factor decrease, respectively, to a value around $0.4 \mathrm{~V}$ and 0.26 compared to $0.52 \mathrm{~V}$ and 0.34 found in devices with CuPc: PCBM, which confirms that the VOC and the FF depend on the HO$\mathrm{MO}_{(\mathrm{CuPc})}-\mathrm{LUMO}_{(\mathrm{C} 60 \text { or PCBM })}$ ).

\section{REFERENCES}

[1] S. Liu, Q. Wang, P. Jiang, R. Liu, G. L. Song, H. J. Zhu and S.-W. Yang, "The Photo- and Electrochemical Properties and Electronic Structures of Conjugated Diphenylanthrazolines," Dyes and Pigments, Vol. 85, No. 1-2, 2010, pp. 51-56. doi:org/10.1016/j.dyepig.2009.10.003

[2] R. Schueppel, R. Timmreck, N. Allinger, T. Mueller, M. Furno, C. Uhrich, K. Leo and M. Riede, "Controlled Current Matching in Small Molecule Organic Tandem Solar Cells Using Doped Spacer Layers," Journal of Applied Physics, Vol. 107, No. 4, 2010, pp. 044503-044506. doi:org/10.1063/1.3277051

[3] R. Aïch, B. Ratier, F. Tran-van, F. Goubard and C. Chevrot, "Small Molecule Organic Solar Cells Based on Phtha- 
locyanine/Perylene-Carbazole Donor-Acceptor Couple," Thin Solid Films, Vol. 516, No. 20, 2008, pp. 7171-7175.

[4] R. Franke, B. Maennig, A. Petrich and M. Pfeiffer, "Long-Term Stability of Tandem Solar Cells Containing Small Organic Molecules," Solar Energy Materials and Solar Cells, Vol. 92, No. 7, 2008, pp. 732-735. doi:org/10.1016/j.solmat.2007.12.001

[5] C. C. Leznoff and A. B. P. Lever, "Phthalocyanine: Properties and Applications," VCH Publisher, New York, 1999, p. 291.

[6] H. Derouiche, H. Ben Miled and A. Belhadj Mohamed, "Enhanced Performance of a CuPc: PCBM Based Solar Cell Using Bathocuproine BCP or Nanostructured $\mathrm{TiO}_{2}$ as Hole-Blocking Layer," Physica Status Solidi $(A)$, Vol. 207, No. 2, 2010, pp. 479-483. doi:org/10.1002/pssa.200925424

[7] H. S. Shin, H. Lim, H. J. Song, H.-J. Shin, S.-M. Parkb and H. C. Choi, "Spontaneous Electron Transfer from C60 to Au Ions: Oxidation of C60 and Hole Doping," Journal of Materials Chemistry, Vol. 20, No. 34, 2010, pp. 7183-7188. doi:org/10.1039/c0jm00783h
[8] M. Manceau, S. Chambon, A. Rivaton, J. L. Gardette, S. Guillerez and N. Lemaître, "Effects of Long-Term UVVisible Light Irradiation in the Absence of Oxygen on P3HT and P3HT: PCBM Blend," Solar Energy Materials and Solar Cells, Vol. 94, No. 10, 2010, pp. 1572-1577. doi:org/10.1016/j.solmat.2010.03.012

[9] O. H. Kwon, K. Park and D. J. Jang, "Photoluminescence Dynamics and Spectra of C60 and C60" in VPI-5 Molecular Cages," Chemical Physics Letters, Vol. 346, No. 3-4, 2001, pp. 195-200. doi:org/10.1016/S0009-2614(01)00967-8

[10] H. Derouiche and V. Djara, "Impact of the Energy Difference in LUMO and HOMO of the Bulk Heterojunctions Components on the Efficiency of Organic Solar Cells," Solar Energy Materials and Solar Cells, Vol. 91, No. 13, 2007, pp. 1163-1167. doi:org/10.1016/j.solmat.2007.03.015

[11] B. Zimmermann, M. Glatthaar, M. Niggermann, M. Riede and A. Hinsch, "Electroabsorption Studies of Organic Bulk-Heterojunction Solar Cells," Thin Solid Films, Vol. 493, No. 1-2, 2005, pp. 170-174. doi:org/10.1016/j.tsf.2005.04.089 